\title{
The Preservation of Wood Pulp Publications
}

\author{
$M r$. Kremer is keeper of the collections, \\ Library of Congress.
}

$\mathrm{I}^{\mathrm{T}}$ IS THE SOLE PURPOSE of this paper to try to answer two basic questions about a serious problem which has long worried the custodians of our research librariesthe disintegration of important volumes printed since about 1870 on wood pulp stock. The questions are, first: Do we as yet have a satisfactory method, either tried or experimentally developed, for the preservation or restoration of the hundreds of thousands of valuable volumes already decayed or progressively decaying because of their inferior paper? And second, if the answer to the first question has to be in the negative: What are the possibilities of an acceptable method being developed before the situation is out of control? To arrive at the answers to these two questions, perhaps we should examine, one by one, the objectives we seek in an acceptable process of preservation. Ideally stated, they may be summarized as follows:

I. Legibility: The restored page should not suffer, in the immediate process or subsequent thereto, any considerable loss in readability.

2. Permanency: The processed unit should be chemically stable in order to withstand normal storage conditions, for ideal ones (air-conditioning at its best) may not be available.

* At a meeting of the Committee on National Needs of the Association of Research Libraries held in Los Angeles last summer, the Library of Congress was requested to prepare a paper on the various current techniques for preservation of deteriorating book materials. The enclosed memorandum, dated November 27, I953, was prepared by Mr. Kremer of the LC staff in response to that request.
3. Durability: The preserved or restored unit should be relatively resistant to tearing and must have folding endurance, assuming, of course, that the processed unit will not have been radically altered in format, and consequently continues to be handled as a printed leaf. ${ }^{1}$

4. Discoloration: There should not be any adverse change in the original color of preserved leaves either immediately incident or subsequent to preservative treatment.

5. Special resistancies: The treated unit should be relatively resistant to attack by mold or mildew and insects, and if possible, to destructive chemical elements, such as sulphur dioxide, in the atmosphere.

6. Utilization: The restored unit or series of units should be in a format that is convenient to use.

7. Rapidity of execution: The actual method of preservation should be one that can be speedily executed for the simple reason that the quantities of decaying pulp publications are already vast, and time is adding to their vastness. Unless speed of treatment can be a characteristic of the method, the process is or will be partly in vain.

8. Economy: Related to the objective of speed, the method must be one of relatively low cost. If not economical and the cost has to be programmed over a period of years, deterioration and tragic loss will continue.

\footnotetext{
1 As a means of preservation, the several forms of microphotography are not discussed in this paper. $\mathrm{Li}$ brarians are either already familiar with their possibilities and limitations or can get access to some published data on the subject; microphotography is not strictly speaking a preservation or restoration method, but
chiefly a means of conserving the record; and while it is the least expensive way to save the record, the problems of making it available or even acceptable to the researcher (and to some librarians), are difficult to resolve, persuasively, administratively and economically.
} 
Unfortunately, most of the older as well as the currently-practiced methods for the preservation of disintegrated paper which are described below can not be applied to wood pulp printed publications. The chief reason is that they would be too expensive, since they still have to be carried out somewhat slowly, by hand for the most part. However high cost and slowness are but two of the limiting factors. It might be well to review the several methods and to point out their advantages and disadvantages in terms of the objectives cited above. While scientists and technicians have been offered the suggestions that possibly gases could be developed to do the job, or that xerography might be considered, without more than suggestions to inspire them, no experimental efforts in those directions seem to have been made. This paper confines itself, therefore, to only the tried techniques.

Also omitted from this discussion are such devices as inlaying, which is a method by which a single sheet is tipped within a surrounding frame of additional paper by use of an adhesive, and the reinforcement of leaves at various weakened points with transparent tapes, including the adhesivecoated plastic types. These techniques provide no additional strength to leaves in their entire areas, which are usually deteriorated, visible or not to the eye; hence they would be inadequate in the case of perserving leaves of wood pulp stock.

\section{SIZING}

While it is primarily the final procedure in the manufacture of most paper, sizing or the resizing of disintegrated paper has sometimes been advocated or practiced as a means of renewing strength by binding together broker paper fibers. A water solution containing a good grade of gelatin has sometimes been used as the sizing bath for this purpose.

Provided the paper is not seriously dis- integrated, some improvement in tensile properties and tearing resistance may be achieved by the sizing process. Unfortunately, wood pulp stock, even as it comes directly from the paper mill, contains certain non-cellulose materials which possess no fiber structure. Once it has become brittle from exposure to light and air, sizing alone is of little value in trying to bind together nonexistent fibers and weakened or broken ones. Books of decayed wood pulp are in many cases noticeably deteriorated or broken at the binding edges of their leaves. One could hardly expect sizing to add enough strength to withstand new sewing, let alone be the sole factor in supplying new binding margins.

\section{THE SILKING TECHNIQUE}

One of the oldest and most widely used procedures until a few years ago, silking is a method by which very thin silk chiffon is pasted to each side of a sheet of paper. It has some advantages but more disadvantages when considered in terms of the objectives of preservation.

When first treated in this manner, a leaf of paper is relatively strong, standing up well under testing methods devised to determine folding and flexing endurance, and quite resistant to tearing. The silk used is relatively transparent, hence the record covered with it does not, initially, suffer any serious loss in legibility.

While the silk chiffon initially adds strength, unfortunately it will not remain strong permanently. It eventually becomes brittle, loses its resistance to tearing, and may take on a discoloration which adversely affects legibility. Pastes used in its application are subject to attack by insects and molds. The process is a slow one and requires highly-skilled craftsmanship to effect, hence it is an expensive one. These considerations would seem to eliminate it as a suitable process for the preservation of wood pulp publications. 


\section{THE TISSUE PROCESS}

This method, although never as widely used as that of silking, is very similar to the latter. The deteriorated leaf has very thin sheets of tissue of all rag stock or of highly purified fibers applied with paste to each of its sides.

While tissue affords some strength, it lacks the initial strength of silk, but as a material, it is a good deal cheaper than silk. To achieve maximum strength, thicker grades of tissue have to be utilized. This, in turn, usually reduces legibility to an objectionable extent. Like the silking process, it is susceptible to attacks by impurities introduced in the paste, by chemical or acidic impurities left in the strengthened leaf itself, by insects attracted by the paste, and by fungi. It, too, is a slow and expensive process. It offers so little for its investment as a permanent means of preservation that it is not a solution to the problem.

\section{TRANSPARENT COATINGS}

In recent years, librarians and archivists seem to have been building their hopes on the development of a cheap method of applying to distintegrated leaves, perhaps by spraying, a transparent coating which would meet most of the requirements of paper restoration. While such sprays have been developed, they do little more than give a protective coating to the surface of a piece of paper. They add little or no physical strength to a weakened leaf. Sometimes, dependent upon the state of disintegration, they can even do more harm than good, as actual tests have demonstrated that they can increase embrittlement under certain conditions. An evaluation of existing spray materials which deposit only a very thin film would indicate that they afford folding endurance. Decayed leaves so treated would seem to remain in frail condition, with their broken fibers still unrepaired. Destructive chemical impurities originally in the sheet would remain therein to carry on the decaying process.

\section{LAMINATION WITH CELLULOSE ACETATE SHEETING}

By lamination is meant the process of applying thermoplastic cellulose acetate film to each side of a leaf of paper, by means of heat and pressure. Good adhesion, or a penetration of the pores of the paper by the thermoplastic film, is obtained only through the use of special equipment with controlled heat and pressure.

Since many deteriorated leaves require greater reinforcement than could be afforded by very thin foils of cellulose acetate alone, one process of lamination allows for the addition of sheets of pure tissue. This overcomes a definite shortcoming of the film. The same process employing tissue for additional strengthening also provides, prior to lamination, for a means of neutralizing the acidity in the disintegrated leaves. Bathing such leaves in chemical solutions containing calcium hydroxide and calcium bicarbonate, not only serves to neutralize existing acidity but also to have a similar influence on any likely to be absorbed in the future.

Lamination, using tissue and the preliminary bathing procedure, has a number of worthwhile features. It results in a product of good legibility; added materials (films and tissue) are relatively permanent and provide resistance to tearing and folding; the process results in no discoloration; it affords resistance to attack by insects and fungi; acidity is neutralized and unlikely to become active again if reabsorbed; and the restored unit continues to be in a useful format.

It is, however, a relatively slow process. Although perhaps four or more times faster than silking and tissuing, it is not rapid. In its present stage of development, there- 
fore, it is too expensive as a means of restoring the hundreds of thousands of decayed wood pulp books.

\section{PRINT TRANSFER}

Almost nothing has appeared in print concerning a treatment which, for want of a better name, has been labeled "print transfer." Actually, it remains in an experimental stage of development, with perhaps less than a hundred deteriorated books having been restored by this unique process. Its developer, Mr. W. J. Barrow, documents restorer of Richmond, Virginia, has very kindly prepared a brief statement concerning it for inclusion in this paper, which is quoted as follows:

"Notes on Print Transfer. During the past four years, efforts have been made to transfer the print from a deteriorated sheet to a sheet of rag paper having a high degree of permanency as a means of preservation of the text. This has a useful application for certain reference books printed on lowgrade paper. The process has good possibilities, and would cost less than photostating, but more than microfilming.

"The process consists of heating and pressing cellulose acetate film sufficiently to cause the ink particles to adhere to the film, but, at the same time, the heat and pressure must be insufficient for the film to penetrate the pores of the paper. This film can be stripped from the sheet and then laminated to a new sheet of rag paper.

"The oxidation and polymerization of the oils of different inks vary. This causes difficulties in always making a good, readable copy. In other words, some books, or portions of books, transfer more easily than others. Here lies the principal problem yet to be solved. Some progress has been made by boiling the sheets in an alkaline solution to convert the oils to a soap. This naturally increases the cost, thus defeating one of the objects of the process.
"This procedure of softening the ink opens up another possible procedure of transfer.. When properly softened, the print can be pressed to another sheet of paper. This sheet can, in turn, be treated and the print transferred again to a permanent rag sheet. Again the variation of the oxidation and polymerization of the print offers problems to be overcome. The materials used in this procedure are less costly than those used in the acetate film method.

"Although this process offers good possibilities, more research and development are needed to produce a product that is consistent in appearance and economical. By use of good materials and procedures, a book of excellent durability and permanency could be produced.

"With the exception of two institutions, the encouragement received has consisted of only kind words. Too frequently, librarians think of the value of a book in terms of the actual cost and not in relation to its demand, value of the contents, etc. The withdrawal of a book when it becomes unusable is generally practiced. Following this path of least resistance is a difficult habit to change. These factors make it questionable as to whether such a process would be profitable even if it were more fully developed."

The writer of this paper very closely inspected many of the books turned out by the process, both before and after treatment, and after rebinding. Books selected for the treatment were typical examples of wood pulp disintegration, many in advanced stages of decay, and all long since beyond rebinding. Their inner (binding) and outer margins were cracked, chipped or actually broken away. Preliminary and final leaves were broken and subject to fluffing to the four winds.

From examination of the processed volumes, anyone would be immediately impressed with the potentialities of print trans- 
fer to solve this long standing problem. While it can be observed that inks do not transfer with complete consistency, the resultant products in the Library of Congress show good legibility. Except for this factor, the technique would seem to result in a product more acceptable than any produced thus far by other restorative processes. Print transfer gets rid of the basic cause of decay-the crumbling pulp paper leaves themselves. The salvaged images can thereafter be preserved by sealing (laminating) them on paper stock that is as pure and as lasting as man can devise, highly resistant to tearing, and of maximum folding endurance. Thereafter, rebinding can be done in a sturdy fashion commensurate with the strength of the leaves.

It has been stated above that print trans- fer is still in an experimental stage of development. Specifically, the ink removal problem remains to be refined. It is certainly conceivable that it can be overcome. Assuming that it will be, still another problem, a fundamental one and of greater magnitude, remains to be wrestled with and solved before print transfer can become the ideal solution to the overall problem. The method must become more mechanized than it is at the moment to make its product reasonable in cost. With modern machines so highly developed to perform continuously multiple operations, it would not seem unreasonable that print transfer could be undertaken by special machinery which would fairly rapidly remove ink as its first operation, and superimpose it on a web of good paper as its second.

\section{Annual Conference of the Graduate Library School, University of Chicago}

The Nineteenth Annual Conference of the University of Chicago Graduate Library School will be held from June I4-I8, I954 and will deal with the subject "The Function of the Library in the Modern College." As in the past the program will include papers by distinguished speakers, representing college and university educators as well as leading librarians in the college library field.

Although preceding conferences have included an occasional paper on some particular phase of the college library problem, this is the first to deal exclusively with this important area in librarianship. The program reflects many of the problems which have been suggested by the field as deserving the kind of intensive treatment which has characterized the Conference papers in the past. The program will include such topics as "The Relationship between the Library and Collegiate Objectives," "The Nature of the Book Collection" (including questions of weeding, optimum size, cataloging and classification, and the characteristics of the "ideal collection"), "The College Library Building," "The Place of the Newer Media in the Liberal Arts Program," "The Liberal Arts Function of the University Library," "Financing the College Library," and "Major Research Problems in College Librarianship." The conference, dealing as it does with problems of broad significance and wide-ranging implications, will be of interest to university as well as college librarians, to library staff members as well as administrators, and to administrative and faculty officers as well as to librarians.

A leaflet describing the detailed program of the Conference will be available soon upon request. For further information address the Dean of the Graduate Library School, University of Chicago, Chicago 37, Illinois. 